\section{The unseen revealed}

\section{A. Howie}

The Beginnings of Electron Microscopy. Edited by Peter W. Hawkes. Academic: 1985. Pp.633. \$88, £67.

DURING the 1920s, the work of Busch and Gabor on the focusing action of short magnetic solenoids in the high speed cathode ray oscillograph, and the separate, celebrated discoveries in electron diffraction, sparked off an idea which some minds - with a faith reminiscent of a mediaeval cathedral-builder - took seriously. That idea was the construction

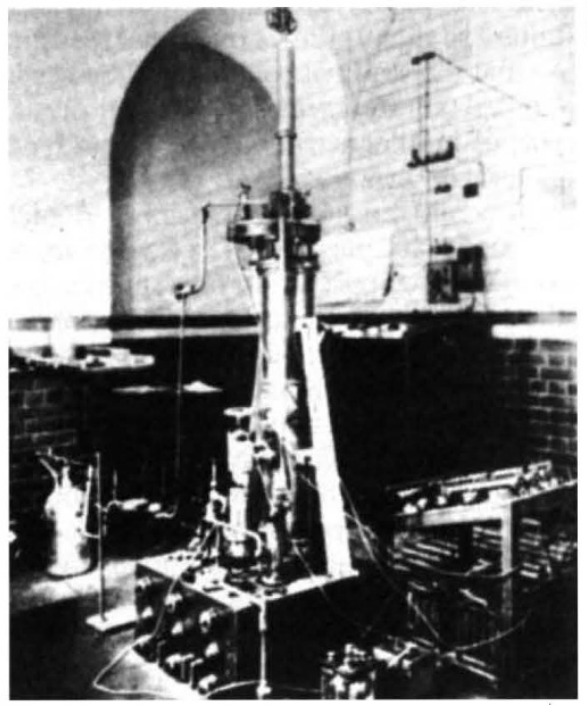

The Met-Vick EMI, the first commercially produced electron microscope. Installed at Imperial College, London in 1936.

of microscopes to surpass the resolution of optical instruments by as much as five orders of magnitude, a limit deduced purely from the electron wavelength.

Here, in partially coherent illumination from a variety of authoritative sources (delightfully illuminated themselves by Cosslett), one can learn how the idea survived the technical obstacles of power supply instability and poor vacua, as well as the deeper problem of lens aberrations. It seems that other difficulties, such as the slump of the early 1930 s and the Second World War (with enemy occupation of Holland and France to be borne by Le Poole, Grivet and Dupouy), were only marginally more serious than the general indifference of optical microscopists. Did they simply exaggerate the beam damage problem? Or were they more realistic about the looming difficulties of specimen preparation and image interpretation described here by Drummond, Hall and Fernandez-Moran?

In this enjoyable collection of reminiscences, Dr Hawkes has unfortunately missed some potentially important contributions because of illness, death or prior publication elsewhere. The brilliant construction by Prebus and Hillier, two graduate students at Toronto, during four months in 1938, of an instrument eventually achieving $100 \AA$ resolution is only briefly mentioned. Less serious is the absence of a major contribution from Ernst Ruska (whose own book, The Early Development of Electron Lenses and Electron Microscopy, appeared in English translation five years ago). His towering achievement is manifest here from different viewpoints. As noted by Mulvey, the transmission microscope producing today's images at atomic resolution follows in all crucial respects the original Ruska design. Restricted, however, by lens aberrations to the small-angle range where coherent scattering effects dominate, the instrument depends on a marriage of electron optics and electron diffraction far closer than anyone then envisaged. Although the reader may trace in Le Poole's account the instrumental foundations of that partnership (also laid by Boersch), sample its fruits in Dupouy's magnificent high-voltage images or sense with Hibi the holographic future, he must turn elsewhere (for example to Fifty Years of Electron Diffraction, published by Reidel in 1981) to appreciate the enormous benefits which the union brought to both disciplines.

As its originator von Ardenne describes, scanning electron microscopy provides a contrapuntal theme even though it shares the same origins with the more conventional transmission method. A much better understanding of electron beam scattering processes is required, however, to exploit fully the rich range of imaging modes available in scanning. Its wide application depends more on ease of specimen preparation and depth of field than simply on resolution. The post-War exploration of these questions and the development of instruments for manufacture are recounted by Oatley and his colleagues. This contribution, as well as Mulvey's, covers two of the three principal manufacturing initiatives in electron optics where, contrary to received doctrine, British industry exploited an idea originating elsewhere. Le Poole and Kanaya treat the early stages of the important Dutch and Japanese electron optical industries.

A third theme, dating from pre-War Germany but little mentioned here, is the field emission microscope. Closer to the simplicity of the Leeuwenhoek microscopes than anything else in electron optics, the field emission tip has fathered the recent spectacular advances in scanning transmission and in scanning tunnelling microscopy. Before long, perhaps, Dr Hawkes will edit a second volume rediscovering in this more recent progress our great debt to the persistent vision of the early pioneers.

A. Howie is Reader in the Cavendish Laboratory, University of Cambridge, Madingley Road, Cambridge CB3 OHE, and President of the Royal Microscopical Society.

\section{Plumbing the depths}

\section{Stephen Moorbath}

Archaean Geochemistry: The Origin and Evolution of the Archaean Continental Crust. Edited by A. Kröner, G. N. Hanson and A. M. Goodwin. SpringerVerlag: 1984. Pp.286. DM87.

UNTIL recently, the Archaean (c. 3,8002,500 Myr ago) was still a great unknown in the earth sciences. This situation has changed dramatically since the 1960 s as a result of two main factors: (i) advances in isotope dating methods and their application to Precambrian rocks, and (ii) the recognition that the oldest exposed gneiss and greenstone terrains retain a wealth of primary igneous, sedimentary and geochemical features.

It was clearly difficult to find an accurate title for a book which contains 13 miscellaneous contributions to a wide field, ranging in style from reviews to research papers and arguably more suited for publication in journals. Thus the principles of geochemistry were no different during the Archaean than they are today. Some workers (including myself) even consider that Archaean continental crust originated and evolved by processes closely similar to those of geologically recent times, albeit much more rapidly because of greater terrestrial radiogenic heat

\section{The Ecology of Rocky Coasts}

\section{Edited by Dr P G Moore and Dr R Seed}

This is probably the most comprehensive volume on the subject of the ecology of rocky coasts ever published. The book is the work of 28 internationally outstanding experts in the field and includes the most recent research and evaluations in this increasingly important area. It provides a complete overview of littoral and sub-littoral communities which will be of immense value to ecologists and marine biologists.

\section{Illus. Boards $£ 40.00$}

\section{Available through all good bookshops} \section{Hoxkder destomghtom}

Mill Road, Dunton Green, Sevenoaks, Kent TN13 2YD 